\title{
ENGENHARIA NAS ESCOLAS, MEIO APROXIMADOR DO CT ÀS ESCOLAS PÚBLICAS
}

\author{
V. C. Oliveira ${ }^{1}$; R. S. Meira ${ }^{2}$ \& N. G. S. D. Montenegro ${ }^{3}$
}

${ }^{1}$ Bolsista e graduando pela Universidade Federal do Ceará (UFC). E-mail: victoroliveira@ det.ufc.br; ${ }^{2}$ Bolsista e graduando pela Universidade Federal do Ceará (UFC). E-mail: rafaeloufc @ gmail.com; ${ }^{3}$ Coordenador de ação extensionista. E-mail: nadja@ det.ufc.br

Artigo submetido em Setembro/2017 e aceito em Novembro/2017

\section{RESUMO}

Com o intuito de permitir uma maior aproximação dos alunos do ensino médio público à vivência acadêmica e a evidenciar a geometria estudada na escola em aplicação, foram selecionadas cinco escolas no entorno do Campus do Pici para uma atividade de extensão. A ação atingiu alunos dos segundos e terceiros anos do ensino médio (cerca de 800 alunos). Destes, foram selecionados 40 que estariam interessados em participar de um minicurso sobre noções de topografia. Assim, foram formadas duas turmas de 20 alunos. Os encontros ocorreram em dois sábados para cada turma, com carga horária de 10 horas, no Laboratório de Geomática Aplicada. Foram abordados temas como: levantamento planimétrico e altimétrico com explanações da teoria e a experimentação, no campo, com instrumentos topográficos (teodolitos, níveis, estações totais). Os resultados alcançados informaram que $96,15 \%$ dos participantes avaliaram como "ótimo" o minicurso, e relataram estar motivados em cursar engenharia na UFC.

PALAVRAS-CHAVE: Topografia; Alunos; Vivência acadêmica; Engenharia.

\section{ENGINEERING IN SCHOOLS, THE TC'S APPROACH TO PUBLIC SCHOOLS}

\begin{abstract}
In order to allow a greater approximation of public high school students to academic life and to apply the geometry studied in the school in a real situation, five schools were selected around the "Campus do Pici" for an extension activity. The action reached students of junior and senior years of high school (about 800 students). Of these, 40 that would be interested in participating in a minicourse on notions of topography were selected. Thus, it was formed two study groups of 20 students each.
\end{abstract}

The meetings took place on two Saturdays for each class, with a workload of 10 hours, in the Laboratory of Applied Geomatics. Topics such as: planimetric and altimetric surveys with explanations of the theory and experimentation in the field with topographic instruments (theodolites, levels, total stations) were studied. The results reported that $96.15 \%$ of the participants evaluated the minicourse as "great" and they expressed being motivated to study engineering at UFC.

KEYWORDS: Topography; Students; Academic Life; Engineering. 


\section{INTRODUÇÃO}

A Topografia é essencial para qualquer projeto de engenharia civil. O ensino desta ciência é de suma importância no campo, tendo em vista que tal atividade faz parte de uma rotina que proporcionará a materialização do projeto de engenharia, essencial para a estabilidade estrutural, segurança e conforto do usuário. Além disso, é de grande valor no campo teórico, cujo destaque se baseia em informar e formar novos profissionais.

No ensino médio, um dos maiores desafios enfrentados por um professor é a aplicabilidade de cada conteúdo. Reproduzir fórmulas e cálculos, sem a conexão com o cotidiano, quase sempre acarreta em um desinteresse dos alunos na busca pelo aprendizado.

Pode-se afirmar que o levantamento topográfico é atividade presente em diferentes obras da construção civil e, com o objetivo de apresentar conceitos básicos da topografia aos alunos do Ensino Médio Público de Fortaleza-CE, assim como divulgar as atividades discentes desenvolvidas na Universidade Federal do Ceará, foi criado o projeto Engenharia nas Escolas.

O objetivo primeiro do projeto foi o de levar a UFC às escolas públicas de forma contextualizada, com material já empregado em aulas de engenharia, para que os alunos começassem a sentir o clima cotidiano de um aluno de engenharia.

O projeto contemplou duas grandes etapas. Na primeira, a equipe foi até os colégios selecionados e realizou a palestra abordando os temas "UFC e suas possibilidades" e "O que faz cada engenheiro". Em um segundo momento, foi ofertado um minicurso com a temática "Noções de Topografia e suas Aplicações", com o objetivo de levar estes alunos para dentro de um ambiente acadêmico e, assim, apresentá-los a uma disciplina de conteúdo profissional do curso de Engenharia Civil, a topografia, que na UFC é realizada no terceiro semestre do curso.

Portanto, o objetivo principal deste projeto foi o de oferecer aos alunos da rede pública de ensino a oportunidade de ampliar os conhecimentos em áreas voltadas à Geomática, com recursos oriundos da Universidade Federal do Ceará (UFC) e com a finalidade de lhes lecionar métodos de levantamentos topográficos, despertando, assim, o interesse nas áreas da engenharia. Dessa forma, os estudantes podem relacionar o conteúdo teórico de geometria, já 
aprendido na escola, e realizar uma aplicação prática, exercida em campo.

Além disso, foi oferecido aos alunos participantes a oportunidade de conhecer as atividades desenvolvidas na universidade, sobretudo acerca dos benefícios, como bolsas de ensino, pesquisa e extensão, além dos programas de intercâmbio entre as universidades estrangeiras. Este momento de vivência, permitiu-lhes saber o que vem a ser "extensão universitária" de forma prática, antes mesmo de chegarem à UFC. Assim, o projeto possibilitou, além do ganho de conhecimento técnico e prático de topografia, um momento de ambiência e aproximação com a UFC.

Ao final do minicurso, os alunos receberam um formulário avaliativo relacionado com a atividade de extensão, onde exprimiram sua avaliação ao longo das atividades. Isso gerou um feedback aos bolsistas e monitores da disciplina, permitindo avaliar os melhores e mais débeis momentos do projeto, para seu futuro aprimoramento. Um teste de conhecimento sobre topografia também foi aplicado (antes e depois das aulas teóricas e práticas), como forma de avaliar a aprendizagem dos estudantes após o curso.

\section{TOPOGRAFIA E SEUS CONCEITOS}

Para o conteúdo apresentado aos alunos das escolas, foram retratados conceitos básicos da topografia e suas relações com a geometria e escalas.

\subsection{O QUE É TOPOGRAFIA?}

A definição de topografia parte da própria palavra, a qual é derivada de duas palavras gregas, sendo elas “topos”, que significa lugar, e "graphen”, que denota descrição, ou seja, a descrição de um lugar.

“A Topografia tem por finalidade determinar o contorno, dimensão e posição relativa de uma porção limitada da superfície terrestre, sem levar em conta a curvatura resultante da esfericidade terrestre. "ESPARTEL (1987)

A topografia é responsável pela representação por projeção ortogonal cotada, evidenciando detalhes de comportamento do solo. Tal projeção é feita sobre uma superfície de nível, denominado de plano topográfico. 


\subsection{APLICAÇÃO DA TOPOGRAFIA}

A topografia é aplicada em diversas áreas de estudos como nas Engenharias, Geologia, Arquitetura, Agronomia etc. Por exemplo, ao alocar uma obra é previamente feito um estudo do terreno e um levantamento topográfico no local em que será construído um determinado empreendimento. Posteriormente, o projeto deve ser alocado assim como foi especificado em planta. A topografia é um agente primário responsável pela aplicação de tal localização.

\subsection{PROCESSOS DE APLICAÇÃO DA TOPOGRAFIA}

Existem dois processos fundamentais no trabalho topográfico, a Topometria e a Topologia. A Topometria evidencia os diferentes métodos e instrumentos disponíveis à obtenção das posições de pontos topográficos e é subdivida em Planimetria e Altimetria. A Topologia tem o objetivo de descrever a área de estudo. Esta última, na prática, representa cartograficamente o terreno usando curvas de nível por exemplo.

A Planimetria busca representar, em um plano horizontal, as projeções dos pontos topográficos medidos em campo e a Altimetria mede a altura destes pontos com relação a um plano de referência de nível.

\subsection{LEVANTAMENTO TOPOGRÁFICO}

A NBR 13.133/94, no item 3.1, define "Levantamento Topográfico é o conjunto de métodos e processos, que, através de medições de ângulos horizontais e verticais, de distâncias horizontais, verticais e inclinadas, com instrumental adequado à exatidão pretendida $[\ldots]$ '..

\subsection{DISTÂNCIAS}

As medições de distâncias horizontais, bem como as angulares, são fundamentais à 
determinação de coordenadas topográficas. Ressaltando que, comumente, os levantamentos realizados em Engenharia são feitos em áreas de extensões reduzidas, desconsiderando a curvatura da Terra.

A distância topográfica entre dois pontos é considerada como a distância horizontal entre eles em relação à projeção do plano na horizontal. Quando não existir possibilidade de medir a distância horizontal, utiliza-se a medição da distância inclinada.

\subsection{ESCALA}

Cândido (2016, p.21) afirma que "Os Mapas e as plantas baixas são representações gráficas reduzidas de superfícies territoriais e de construções, respectivamente. Para elaboração é necessário relacionar as dimensões reais com as do desenho correspondente[...]". A razão entre a distância medida no desenho e suas dimensões reais é denominada de escala.

\section{MATERIAIS E MÉTODOS}

Para o projeto de extensão, foram selecionadas 5 escolas públicas: EEEFM Antônio Bezerra, EEEFM Antonieta Siqueira, CAIC Raimundo Gomes de Carvalho, EEEP Júlia Giffoni e EEEP Joaquim Nogueira. As duas últimas são de ensino profissionalizantes e as primeiras são de ensino médio regular. Elas estão localizadas próximas ao entorno do Pici, conforme a Figura 1.

FIGURA 1- ESCOLAS ESTADUAIS SELECIONADAS

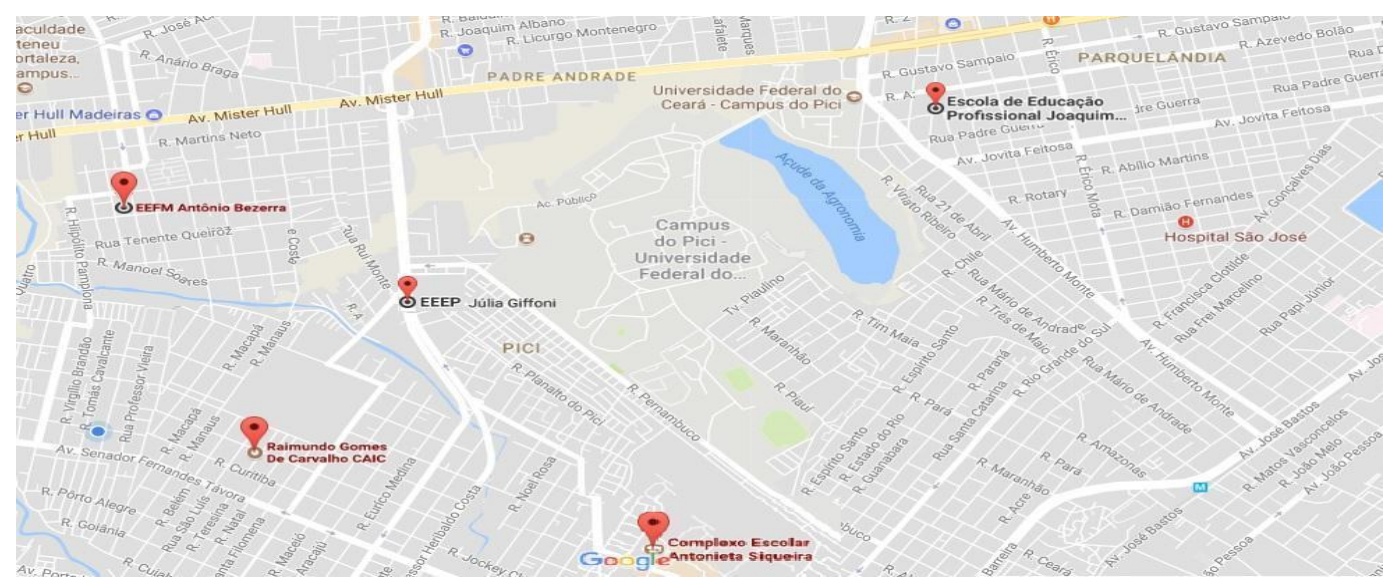

Fonte: Google Maps 
Os bolsistas entraram em contato com os diretores ou coordenadores das respectivas escolas onde fora assinado um termo de compromisso com o projeto.

Inicialmente, foi previsto que cerca de 1000 alunos do segundo e terceiro ano do ensino médio, uma média de 200 por cada escola, pudessem participar da primeira etapa do projeto, assistindo a palestra.

Na primeira parte da palestra, fora explicado como o projeto surgiu, falou-se sobre a UFC e alguns dos seus projetos de extensão, intercâmbio, restaurante universitário e tipos de bolsas. Em um segundo momento, falou-se sobre os cursos de graduação do centro de tecnologia, dando ênfase ao curso de Engenharia Civil. As palestras tiveram a duração cerca de 90 minutos em cada escola, em algumas houve mais de uma seção por conta de espaço físico e disponibilidade de horário de diferentes turmas da escola.

Antes do encerramento de cada palestra, falou-se sobre como seriam as atividades do minicurso de noções de topografia e de suas aplicações, com suas respectivas datas e horários. Todos os alunos interessados em participar do minicurso realizaram inscrição online em plataforma virtual, criada pelos monitores. Foram um total de 45 inscrições. Dessa população, foi escolhida uma amostra de alunos com 40 vagas para engajar no projeto de topografia com aulas teóricas e práticas. Estes alunos, por fim, foram divididos em 2 turmas de 20 pessoas.

As aulas ocorreram em dois sábados para cada turma, com carga horária de 10 horas, no laboratório de Geomática Aplicada. Os temas abordados foram: levantamento planimétrico e altimétrico, com explanações da teoria e a experimentação no campo com instrumentos topográficos. Ao fim do minicurso, todos receberam certificação assinada pelos bolsistas e pela coordenadora do projeto. As figuras 2 e 3 exibem a representação dos equipamentos utilizados durante o curso e sua integração com os alunos.

Os instrumentos topográficos usados nas aulas em campo foram: Nível digital DL-201 Ruíde, Estação Total RTS R3 Ruíde, Régua com código de barras, Baliza, Tripé Foif e prisma. Os instrumentos e os levantamentos possuem tolerâncias diferentes por tipo, todos normatizados pela NBR 18333:1994, que dispõe das normas para a execução dos levantamentos topográficos. Contudo, para fins didáticos, não foi abordado o conteúdo de tolerância e erros topográficos durante o minicurso, apenas citados de forma superficial. 
FIGURA 2 - LEVANTAMENTO ALTIMÉTRICO

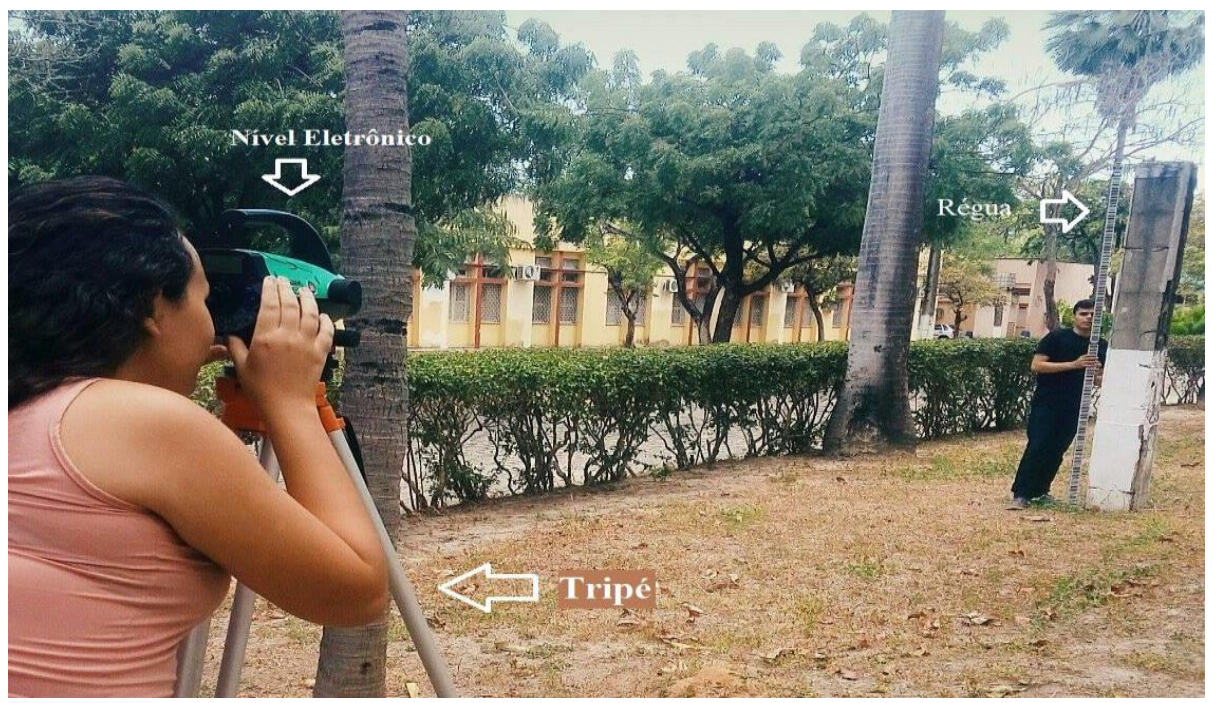

Fonte: Autores

FIGURA 3 - LEVANTAMENTO PLANIMÉTRICO

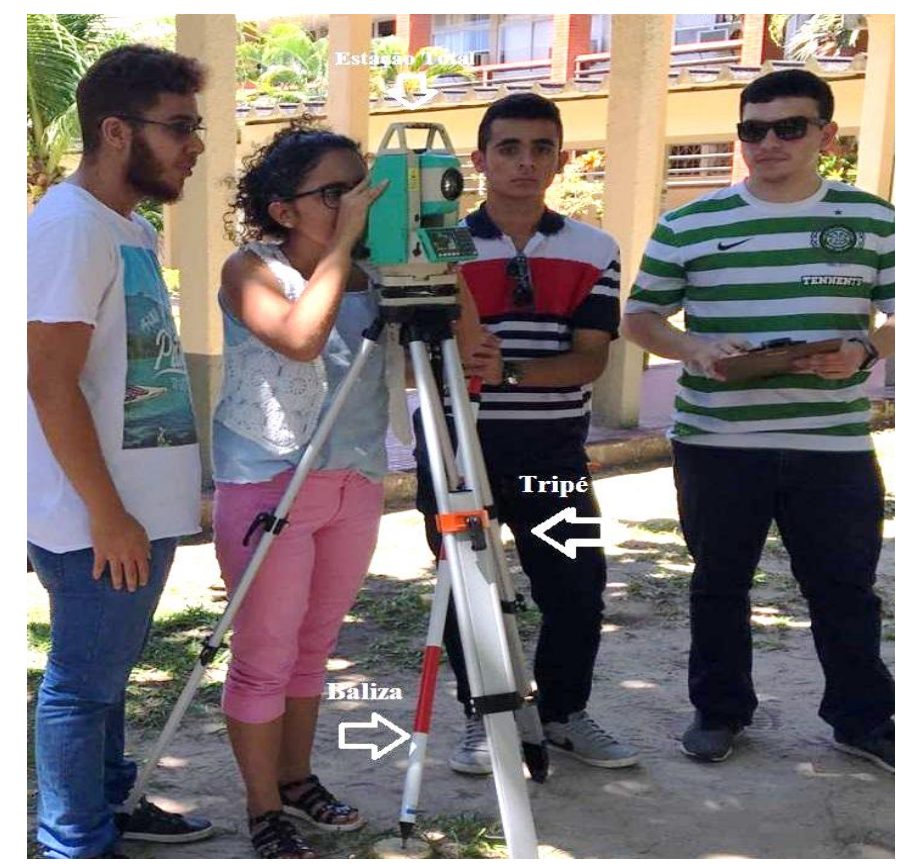

Fonte: Autores

Para avaliar o nível da palestra foi realizado um questionário online, cujo feedback 
ajudaria os monitores a preparar as próximas apresentações nos anos seguintes de projeto. Para medir o nível de conhecimento adquirido dos alunos com o curso, foram aplicadas provas objetivas de conhecimentos topográficos gerais antes das aulas, como mostra a Figura 4 e depois do minicurso como mostra a Figura 5. Como forma de medir esse resultado foram separadas as notas em 5 classes de distribuição de frequência e usado média e desvio padrão simples.

FIGURA 4 - QUESTIONÁRIO PRÉ-MINICURSO (ADAPTADO)

1) Se você fosse ver um terreno e observou que a parte da frente está mais alta do que a parte do fundo do terreno, você diria que o terreno está em declividade (Descendente / $\underline{\text { Ascendente) da }}$ frente para o fundo. Circule a palavra certa para completar esta frase.

2) Você comprou uma casa em fortaleza-CE que tem sua frente voltada para o nascente, qual o ponto cardial que corresponde o nascente: ( ) norte; ( ) sul; ( ) oeste; e ( ) leste.

3) Qual o nome de algum instrumento topográfico que você conhece, ou já ouviu falar:

4) Se você mediu uma calçada com uma trena, e identificou na trena o comprimento de 10,35 m. Quanto centímetros tem esta calçada? E quantos milimetros?

5) Você foi visitar uma fazenda e viu uma elevação e um vale. Diga o que você entende por "elevação" e por "vale":

6) No seu entendimento, o que você entende por "levantamento topográfico":

7) A bússola é o instrumento topográfico que indica a direçäo do norte magnético da terra, através de uma agulha imanada, em qualquer lugar onde este instrumento se encontre. suponha que você levou uma bússola para a sua casa e verificou que a agulha apontou para a direção de seu quintal. Pergunta, qual a direção que fica a frente de sua casa?

( ) norte; ( sul; ( ) oeste; ( ) leste.

8) Uma sala retangular mede $10 \mathrm{~m}^{2}$ de área. Os comprimentos das paredes desta sala são:
( ) $5 \mathrm{~m}$ e $5 \mathrm{~m}$
( ) $4 \mathrm{~m}$ e $6 \mathrm{~m}$;
( ) $2 \mathrm{~m}$ e $5 \mathrm{~m}$;
( ) Nenhuma das opções.

9) O que você entende por Distância horizontal e Distância vertical?

10) Você está afastada de um poste de $5 \mathrm{~m}$, e olha para o topo deste poste e descobre que o ângulo formado pelo plano horizontal e o plano de sua visão é de 45:. Você pode informar qual a altura deste poste:

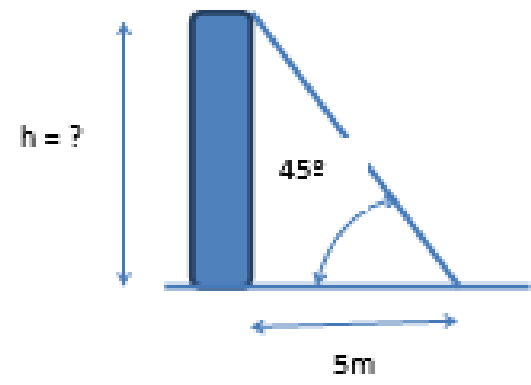

Fonte: Autores 


\section{FIGURA 5 - QUESTIONÁRIO FINAL DO MINICURSO (ADAPTADO)}

1) Ė uma representação reduzida de uma dada área do espaço geográfico. Um mapa temático, por sua vez, é uma representação de um espaço realizada a partir de uma determinada perspectiva ou tema, que pode variar entre indicadores sociais, naturais e outros.
(a) Mapa;
(b) Levantamento topográfico;
(c) Vista horizontal
(d) Outra opção.

2) Ė um esboço cartográfico de uma determinada área, ou em outras palavras, um mapa produzido sem escala e sem os procedimentos padrões na sua elaboração, servindo apenas para a obtenção de informações gerais de uma área observada.
(a) Croqui;
(b) Desenho;
(c) Rascunho;
(d) Outra opção.

3) Ė a proporção entre a área real e a sua representação em um mapa. Geralmente, aparece designada nos próprios mapas na forma numérica e/ou na forma gráfica.
(a) Texto
(b) Escala
(c) Croqui
(d) Outra opção.

4) Ė a utilização de símbolos em mapas para definir algumas representações e está sempre presente em mapas temáticos. Alguns símbolos cartográficos e suas legendas são padronizados para todos os mapas, como o azul para designar a água e o verde para indicar uma área de vegetação, entre outros.
(a) Croqui
(b) Legenda
(c) Plantas
(d) Outra opção.

5) Ė a distância, medida em graus, entre qualquer ponto da superfície terrestre e a Linha do Equador, que é um traçado imaginário que se encontra a uma igual distância entre o extremo norte e o extremo sul da Terra.
(a) Longitude
(b) Curva de Nivel
(c) Latitude
(d) Outra opção.

6) Ė a distância, medida em graus, entre qualquer ponto da superfície terrestre e o Meridiano de Greenwich, outra linha imaginária que é empregada para definir a separação dos hemisférios leste e oeste.
(a) Paralelos
(b) Latitude
(c) Longitude
(d) Outra opção.

7) São as linhas imaginárias traçadas horizontalmente sobre o planeta ou perpendiculares ao eixo de rotação terrestre. Os principais são a Linha do Equador, os Trópicos de Câncer e Capricórnio e os Círculos Polares Artico e Antártico.
(a) Paralelos
(b) Meridianos
(c) Cotas
(d) Outra opção.

8) São as linhas imaginárias traçadas verticalmente sobre o planeta ou paralelas ao eixo de rotação terrestre. O principal é o de Greenwich, estabelecido a partir de uma convenção internacional.
(a) Paralelos
(b) Meridianos
(c) Perpendiculares
(d) Outra opção.

9) $\dot{E}$ a combinação do sistema de paralelos e meridianos com base nas longitudes e as latitudes para endereçar todo e qualquer ponto da superfície terrestre
(a) Curvas de Nível
(b) Pontos Geográficos
(c) Coordenadas Geográficas
(d) Outra opção.

10) E uma linha ou curva imaginária que indica os pontos e áreas localizados sob uma mesma altitude $e$ que possui a sua designação altimétrica feita por números representados em metros.
(a) Curvas de Nivel
(b) Coordenadas Geográficas
(c) Paralelos
(d) Outra opção.

\section{Fonte: Autores}

Por fim, para aferir o nível de satisfação dos alunos, foram aplicados questionários que tentaram medir o grau de satisfação do desempenho do facilitador e da equipe (na condução do minicurso), os equipamentos e o laboratório em "ótimo, bom, regular e ruim". Foi demandado aos alunos uma "nota geral" para o minicurso, variando de zero a dez, a importância do minicurso e influência do mesmo na motivação de se cursar ensino superior ou trabalhar com topografia no futuro. Vale ressaltar que foi disposto, ao final, espaço para opiniões de melhoria do minicurso. 


\section{RESULTADOS E DISCUSSÕES}

A seguir, apresentam-se os resultados, seguindo o procedimento estatístico, caracterizado na seção de materiais e métodos, separando os resultados em classes de distribuição de frequência.

- Com relação às provas objetivas, aplicadas no início e no final do curso, foram obtidos os seguintes resultados. Após a aplicação da primeira prova, obteve-se média de desempenho geral de 66,35\% de acertos, com desvio padrão de $27,5 \%$.

Tal fato é retratado no gráfico 1.

\section{GRÁFICO 1 - NOTAS DISTRIBUIIDAS EM CLASSES DO QUESTIONÁRIO 1}

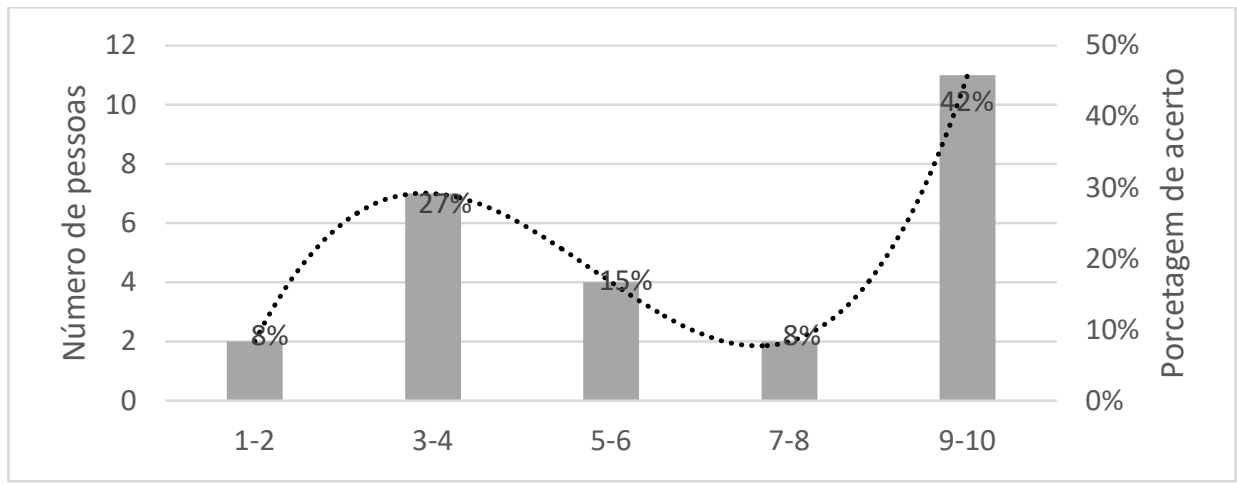

Fonte: Autores

- Com relação ao segundo teste (referente ao pós-minicurso), obteve-se média de desempenho geral de $62,8 \%$ de acertos, com desvio padrão $19,5 \%$. Tal fato é retratado no gráfico 2 .

GRÁFICO 2 - NOTAS DISTRIBUÍDAS EM CLASSES DO QUESTIONÁRIO 2.

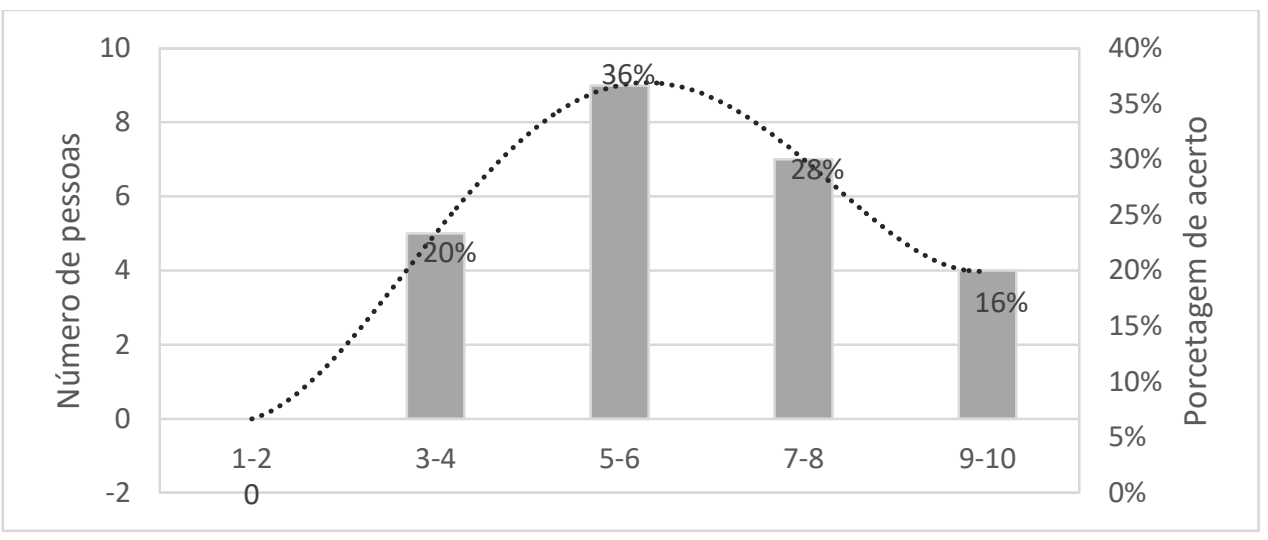

Fonte: Autores

Foi também mensurado o nível de satisfação do minicurso (variando entre ótimo, 
bom, regular e ruim). Os resultados foram os seguintes (o gráfico 3 também retrata a questão):

- $96,2 \%$ dos alunos avaliaram o minicurso como ótimo e 3,8\% como regular;

- $73 \%$ consideraram os facilitadores como ótimo e $27 \%$ como regular;

- $65 \%$ avaliaram o laboratório como ótimo e 35\% como regular;

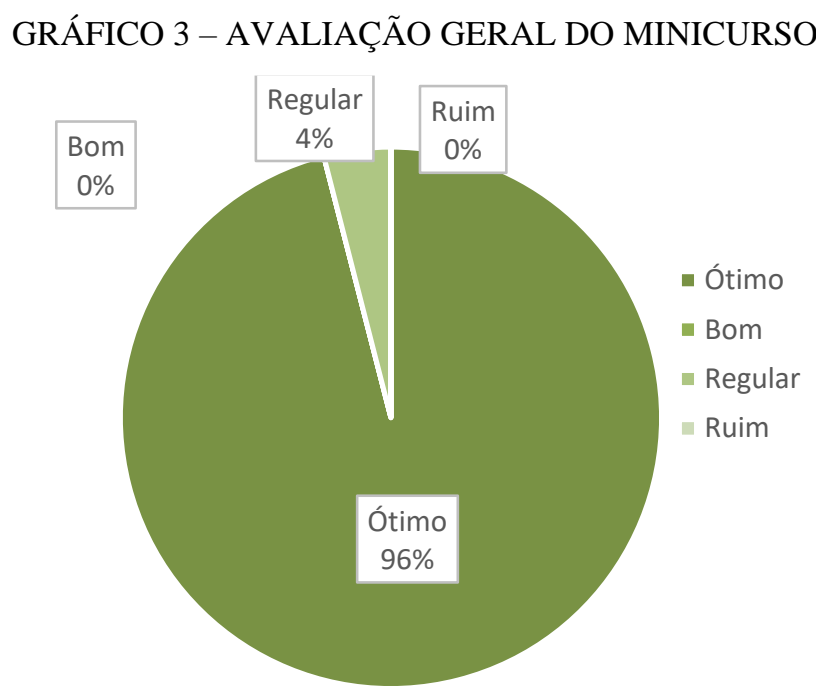

Fonte: Autores

Por fim, quanto à influência agregada do minicurso ao estudante (escala de 0 a 10):

- Foi obtida a média geral de 9.4 dada para a relação de importância da topografia à sociedade.

- Foi obtida a média geral de 9.27 dada para a influência do projeto de extensão (palestra e minicurso) em uma possível escolha profissional/acadêmica futura do aluno.

\section{CONCLUSÃO}

O resultado do primeiro teste do minicurso, representado pelo gráfico 1, apresentou uma disparidade no conhecimento prévio de cada participante. Assim sendo, a missão dos monitores era de equilibrar o desempenho dos estudantes, de forma com que todos os alunos conseguissem assimilar o conteúdo da melhor maneira possível, obtendo resultados produtivos. No último teste, foi visto que as turmas conseguiram ter um desempenho tendendo a uma distribuição normal, representado no gráfico 2 pelo histograma com curva de 
Gauss. Portanto, apesar de a média geral ter diminuído de 66,35 para 62,8, o número de estudantes com notas entre 5-10 subiu de 65\% para $80 \%$, revelando que boa parte da turma conseguiu ter um crescimento satisfatório no entendimento geral dos assuntos lecionados.

Os demais resultados expostos justificam a ação e sustentam o nível de excelência e de importância do minicurso. A apuração da satisfação revelou um nível superior a 90\% de entusiasmo dos alunos pelas aulas, porém ainda precisa-se melhorar alguns índices, como a estrutura do laboratório.

Este trabalho representou o primeiro contato de muitos alunos de escola pública com a UFC e com o Campus do Pici. Os ensinamentos lecionados não foram ligados somente à geomática aplicada, foram também em relação ao cotidiano do estudante universitário, das oportunidades de se estudar em uma universidade de referência nacional e do crescimento profissional e de qualidade de vida que o estudo trás para a vida de todos.

Além disso, o projeto resultou em um ganho pessoal. Tanto para os alunos, que se demonstraram motivados a cursar o ensino superior, quanto para os monitores, que assimilaram a filosofia do centro de tecnologia, sendo capazes de unir os estudantes em um ambiente de aprendizagem de engenharia, porém com ganhos de valores humanos.

\section{REFERÊNCIAS}

ASSOCIAÇÃO BRASILEIRA DE NORMAS TÉCNICAS (ABNT). NBR 13133: Execução de levantamento topográfico. Rio de Janeiro, 1994. 35p.

CÂNDIDO, Luana Patrícia Silva et al. Áreas e distâncias na agrimensura: uma proposta didática de modelagem matemática para o ensino fundamental e médio. 2016.

ESPARTEL, Lelis. Curso de topografia. Globo, 1987.

GOOGLE, Google Maps. Disponível em:<https://www.google.com.br/maps/place/EEEP+J\% C3\%BAlia+Giffoni/@.7485532,8.5868168,17z/data=!3m1!4b1!4m5!3m4!1s0x7c74be9f5277 0c7:0x7de019b89c82859c!8m2!3d-3.7485532!4d-38.5846281>. Acesso em: 12 de setembro de 2017. 